We thank, for providing or facilitating access to the data, Rosalia Munoz-Arroyo, Jennifer Bishop, Chris Povey, Matthew Armstrong, Craig Dougan, Mag Conway, James McNally, and Bill Gold at ISDScotland; Malcolm Campbell and Cath Macdonald at the Royal College of General Practitioners, Scotland; and Alasdair Coutts at the Primary Care Clinical Informatics Unit, University of Aberdeen.

Contributors: DM, MS, and GW jointly contributed to the design and interpretation of the study and the writing of the paper. DM and MS collated the data, and DM undertook the analysis. GW wrote the final version of the paper with contributions from DM and MS. GW is guarantor.

Funding: DM and MS were funded by the Platform Project when the majority of this work was undertaken. The Platform Project is a collaborative venture between the Universities of Aberdeen,
Dundee, Edinburgh, and Glasgow, with ISDScotland and the Royal College of General Practitioners. It was jointly funded by the Chief Scientist Office (RDG HR01012) and the Scottish Higher Education Funding Council (OOB/3/67).

Competing interests: None declared.

Ethical approval: Not needed.

1 Noble M, Smith G, Wright G, Dibben C, Lloyd M, Ratcliffe A, McLellan D, Sigala M, Anttila C. Scottish indices of deprivation 2003. Edinburgh: Scottish Sigala M, Anttila

2 McKeon AJ. Personal medical services pilots under the NHS (Primary Care) Act 1997: a comprehensive guide, 1997. London: Department of Health, 1997.

3 Watt G. The inverse care law today. Lancet 2002;360:252-4.

4 Scottish Executive. Our national health: a plan for action, a plan for change. Edinburgh: Scottish Executive Health Department, 2000.

(Accepted 6 September 2005)

\title{
Overprescribing antidepressants to children: pharmacoepidemiological study in primary care
}

\author{
Kathleen Bennett, Mary Teeling, John Feely
}

Depression is associated with considerable morbidity and risk of suicide. About $20 \%$ of adults and $2 \%$ of those aged 0-18 years are affected at anytime. ${ }^{1}$ Although widely used to manage adult depression, no antidepressants are licensed for use in children. Recent attention has focused on the potential risk of suicide in children. We aimed to evaluate the level of use of antidepressants in adults and children in Ireland, the drug type and duration of use, and the changes in prescription rates over time.

\section{Participants, methods, and results}

We used the General Medical Services' claims database. The scheme, which is means tested, provides free health services to about $30 \%$ of the Irish population (representing 1.24 million people) and $28 \%$ of all children. $^{2}$ All prescription items are coded using WHO's anatomical therapeutic chemical classification (ATC) and basic demographic information (age and sex) are recorded. As age is categorised we classified people aged $0-15$ years and $\geq 16$ years as children and adults respectively. We identified people who had been prescribed antidepressants (ATC N06A-X) between January 2001 and August 2004. Prevalence was based on 2003 data. We used Poisson regression to examine trends, expressed as the average monthly relative change in prescription rate (that is, a rate ratio of 0.98 represents as a relative rate change of $-2 \%$ ). We used SAS 9.0 (SAS, Cary, North Carolina) for all analyses.

In 2003, antidepressants were prescribed to 1079 children, representing $0.43 \%$ of the eligible population, and to 153863 adults, representing $16.9 \%$ of the population (ages 16-24, 9\%; 25-74, 17.9\%; $\geq 75$ years, $18.3 \%$ ). Girls (odds ratio $1.60,95 \%$ confidence interval 1.42 to 1.80$)$ and women $(1.40,1.38$ to 1.42$)$ were significantly more likely to receive antidepressants than their male counterparts. Type of antidepressant was similar in adults and children, with selective serotonin reuptake inhibitors the most commonly prescribed group. About 58\% of children received only one prescription for antidepressants, but $19.4 \%$ received three or more months of prescriptions in 2003. In contrast, $23.5 \%$ of adults received just one prescription, and $66.5 \%$ received three or more months' worth, reflecting more chronic use.

The test for interaction of time by population group (adult or child) was significant $(\mathrm{P}<0.001)$, indicating different trends for the two groups, as was the interaction of time by type of antidepressant (selective serotonin reuptake inhibitor versus tricyclics) for children $(\mathrm{P}<0.001)$.

The overall trend in antidepressant prescribing in children showed a significant reduction between January 2001 and August 2004 (figure; rate ratio - 0.45\%, $95 \%$ confidence interval $-0.60 \%$ to $-0.30 \%$, $\mathrm{P}<0.001)$. A similar trend was noted for tricyclic antidepressants $(-1.80 \%,-2.10 \%$ to $-1.50 \%)$. However prescribing patterns for selective serotonin reuptake inhibitors in children did not show an overall downward trend $(0.17 \%,-0.03 \%$ to $0.37 \%, \mathrm{P}=0.091)$.

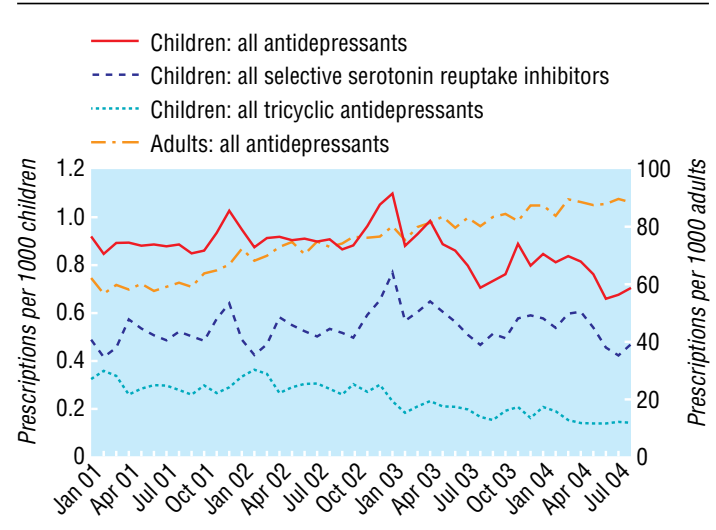

Prescribing rate of antidepressants in Irish children and adults from January 2001 to August 2004

\section{Papers p 1435}

Department of Pharmacology and Therapeutics, Trinity Centre for Health Sciences, St James's Hospital, Dublin 8, Republic of Ireland

Kathleen Bennett statistician Mary Teeling lecturer in clinical pharmacology John Feely professor of pharmacology and therapeutics

Correspondence to: K Bennett bennettk@tcd.ie

BMJ 2005;331:1451-2 


\section{What is already known on this topic}

Although antidepressants are widely used to manage depression in adults, no agents are licensed for use in children, and risk of suicide is a concern

\section{What this study adds}

Prescribing selective serotonin reuptake inhibitors in adults to children has not significantly reduced despite safety warnings

In contrast, the adult pattern showed a statistically significant upward trend $(1.06 \%, 1.05 \%$ to $1.07 \%$, $\mathrm{P}<0.001)$.

\section{Comment}

We found a significant decrease in antidepressant prescribing in children over time (except for selective serotonin reuptake inhibitors), whereas prescribing increased in adults. Most children received only one month's treatment, although such use may have limited efficacy."

Several limitations to our study may have biased our findings. Diagnostic data were not available and social disadvantage (a factor associated with depression and other morbidities) is over-represented in the database. Such children will often have reduced access to specialist health care, potentially necessitating pharmacotherapy in the short term. The results suggest that selective serotonin reuptake inhibitors continue to be prescribed for the management of childhood depression, despite warnings from regulatory authorities. ${ }^{45}$ Prescribers may need to receive regular reminders about potential safety problems and efficacy with use of antidepressants in children, especially in the first weeks of treatment, to ensure their appropriate use.

We thank the General Medical Services (Payments) Board for the use of the prescribing database.

Contributors: KB and MT planned, designed, analysed, and drafted the article. KB, MT, and JF interpreted and approved the final version. $\mathrm{KB}$ is guarantor.

Ethical approval: Not needed

Funding: None.

Competing interests: None declared.

1 Costello EJ, Pine DS, Hammen C, March JS, Plotsky PM, Weissman MW et al. Development and natural history of mood disorders. Biol Psychiatry 2002;52:529-42.

General Medical Services (Payments) Board. Financial and statistical analysis of claims and payments, 2003. Dublin: GMS Payments Board, 2003.

Paykel FS, Priest RG. Recognition and management of general practice: consensus statement. BMJ 1992;305:1198-202.

4 Irish Medicines Board. Statement on behalf of the irish medicines board [on selective serotonin reuptake inhibitors]. Dublin, IMB, 2003. www.imb.ie/ safety.asp?nav $=11$ \&action $=$ view\&safety_item_id $=23$ (accessed 6 Dec

2005)

SSRI and venlafaxine use in children. Curr Probl Pharmacovigilance 2003, 29(September):4. www.mhra.gov.uk/home/idcplg?IdcService =SS_GET PAGE\&useSecondary $=$ true\&ssDocName $=$ CON007449\&ssTargetNode Id $=368$ (accessed 6 Dec 2005)

(Accepted 16 August 2005)

\section{One hundred years ago}

\section{The medical student of to-day}

A WRITER in the St.James's Gazette bewails the "passing" of the medical student. He explains that, although there are still young men who devote themselves to the study of medicine, "all that made the medical student distinctive-the gay, irresponsible, irrepressible youth of our imaginations and of our literature-has faded into the light of common day, and the difference between the medical student of these years of grace and the theological student, for example, is that one is studying the Thirty-nine Articles and the other the metacarpal articulations." The modern student, we gather, is bored by the lectures he has to attend, and a genuine interest in his work, or a real scientific curiosity, is rare.

Nevertheless, having the fear of the examiner before his eyes, he reads hard, but the whole system of examinations is "soul-killing, destroying originality, destroying continuity, and bestowing the prize on the man who patiently 'swots' up his subjects and mechanically gives forth the answers he has been told to give." That lectures often cause boredom is true enough, but that is not altogether the fault of the student. That the passing of examinations is to a considerable extent a mechanical art cannot be denied, but that is mainly the fault not of the system, but of the way in which it is too often applied. As long as mere book knowledge is accepted as a passport by those who guard the portals of medicine, so long will cramming continue. But for keen interest in his work the medical student compares favourably with any other class. This is a frequent subject of remark at the older universities, where he is marked out among his fellows by the eagerness with which be strives after knowledge. He has to work much harder than other students, and that necessarily leaves him less time for frolicking. No one, however, better knows how to put in practice the maxim Dulce est desipere in loco. Fortunately, drinking and other undesirable manifestations of the "flamboyancy and sparkle" which are said to be wanting in the medical student of to-day are now generally looked upon as "bad form." The "chronic," who was the prototype of the medical student as painted by Dickens, Albert Smith, and Thackeray, has disappeared under the stress of the modern curriculum. He is as much out of place in a modern school as Sawyer, late

Nockemorff, would be in modern practice. If the medical student has lost in "flamboyancy," he has gained vastly in true manliness of character, as well as in scientific spirit and range of mental outlook-a result of a change in thought and feeling with which the profession and still more the public have every reason to be satisfied.

(BMJ 1905;ii:971)

We welcome articles up to 600 words on topics such as A memorable patient, A paper that changed my practice, My most unfortunate mistake, or any other piece conveying instruction, pathos, or humour. Please submit the article on http://submit.bmj.com Permission is needed from the patient or a relative if an identifiable patient is referred to. We also welcome contributions for

"Endpieces," consisting of quotations of up to 80 words (but most are considerably shorter) from any source, ancient or modern, which have appealed to the reader. 